\title{
Perforator-Sparing Abdominoplasty Technique in the Presence of Bilateral Subcostal Scars after Gastric Bypass
}

\author{
Ulrich M. Rieger, MD'; Markus Aschwanden, MD2; Dominik Schmid, MD; \\ Daniel F. Kalbermatten, MD'; Gerhard Pierer, MD'; Martin Haug, MD'
}

\author{
${ }^{1}$ Department of Plastic, Reconstructive and Aesthetic Surgery, and ${ }^{2}$ Department of Internal \\ Medicine, Division of Angiology, University Hospital of Basel, Basel, Switzerland
}

Background: The number of patients after gastric bypass being referred to plastic surgery units for secondary plastic surgery procedures is increasing. The characteristic abdominal deformity includes a draping apron of panniculus, occasionally associated with previous transverse surgical scars in the upper abdomen. Often a limited abdominoplasty of the low transverse type with limited undermining only up to the level of the umbilicus is performed in order not to compromise blood supply in the zone between the old transverse and the new transverse scar.

Method: We propose a new, modified and safe surgical technique to perform a complete abdominoplasty with wide undermining up to the xiphoid process in patients with preexisting transverse subcostal scars after gastric bypass surgery, by selectively dissecting and preserving one to three periumbilical abdominal wall perforator vessels to secure flap blood supply. Vessel tunnelling through the rectus sheath and muscle and ligation of the cephalad branch of the perforator provide sufficient flap mobility without perforator tension or traction. Flap undermining is performed around these perforator vessels. To match dissected flap perforators with blood-flow, we performed postoperative color-flow duplex scanning.

Results: We treated two patients according to this new technique. In both cases the postoperative course was uneventful and a good aesthetic result was achieved.

Conclusion: We conclude from our experience that with this perforator-sparing abdominoplasty technique, safe and complete abdominoplasty can be performed with no additional risk of complications and that a good cosmetic result can be achieved in patients after open gastric bypass surgery.

Key words: Perforator, abdominoplasty, scar, obesity

Correspondence to: Ulrich M. Rieger, MD, Department of Plastic, Reconstructive and Aesthetic Surgery, University Hospital of Basel, Spitalstrasse 21, 4031 Basel, Switzerland. Fax: ++41 61 265 7301; e-mail: riegeru@uhbs.ch

\section{Introduction}

The number of patients being referred for abdominoplasty following gastric bypass (GBP) surgery ${ }^{1}$ is constantly increasing. In these patients, we occasionally encounter a long transverse supraumbilical or subcostal scar compromising blood supply from the superior epigastric arteries. The left oblique or left and right oblique incisions are the standard incisions of some surgeons for bariatric surgery, because of a very low rate of incisional hernia compared to vertical midline incisons..$^{2-4}$ Scarring after oblique incisions on both sides is a real problem and a great limitation to performing full abdominoplasty later, due to a higher postoperative risk of complications. ${ }^{5}$ On the one hand, previous scarring and subsequent subdermal fibrosis can compromise blood supply, leading to partial or complete tissue necrosis. On the other hand, patients following GBP need full abdominoplasty by extensive lifting also above the umbilicus. Limiting the mobilization of the abdominal flap leads to preservation of vascular zones, ${ }^{6}$ but not to an esthetically acceptable result. Traditionally, to perform full abdominoplasty with lifting effects both above und below the navel, a two-stage procedure was necessary: the first step was a limited abdominoplasty of the lower abdomen, and the second step consisted of a reversed abdominoplasty with scar positioning in the submammary folds to complete satisfactory body contouring. Beside the two-stage procedure itself, the main disadvantage is an insensible abdominal skin between the two transverse scars. 
We describe a new technique that allows performance of a full abdominoplasty in patients with transverse supraumbilical or subcostal scars after open GBP surgery as a single-stage procedure. This technique appears not to have higher postoperative complication rates than the traditional aforementioned two-stage procedure.

\section{Materials and Methods}

\section{Operative Technique}

The abdominoplasty procedure was performed by a single faculty member (M.H.), under general anesthesia with muscle relaxation. Basically, the operative procedure was done according to Pitanguy. ${ }^{7}$ However, in order to prevent hypoperfusion of the flap, we selectively dissected and perserved 1 to 3 abdominal wall perforator vessels. Vessel tunnelling through the rectus sheaths and rectus muscles and ligation of the cranial perforator branches provided sufficient flap mobility without perforator tension or traction. Flap undermining was performed around those perforator vessels (Figure 1).

The abdominal flap was then elevated to the xiphoid process centrally and the costal margins laterally, and excess skin and subcutaneous tissue were excised. Hereby the lifting effect could be extended all over the abdominal flap up to the xiphoid. The umbilicus was circumcised and reinserted in a triangular incision on the abdominal flap. In presence of

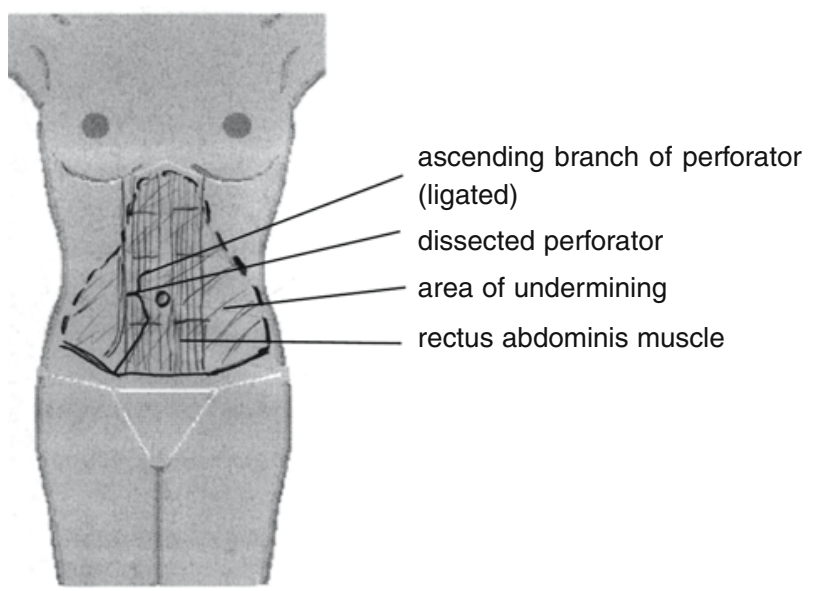

Figure 1. Outline of perforator-sparing abdominoplasty. Displayed are the area of undermining, the rectus abdominis muscles and one exemplary dissected perforator with ligated ascending branch. true diastasis of the rectus muscle, midline suture plication of the fascia was performed, beginning below the xiphoid process and continuing down to the pubis. Layered closure of the abdominal wound was performed over two suction drains. Cephazoline 1 gram was administered intravenously 1 hour preoperatively for antibiotic prophylaxis.

In order to measure postoperative blood-flow through the dissected perforator vessels, we performed color-flow duplex imaging 10 weeks postoperatively. Duplex imaging was done as previously described, ${ }^{8,9}$ the patient was examined supine, and a Siemens Sonoline VERSA PRO apparatus (Siemens, Munich, Germany) was used.

\section{Case Reports}

\section{Case 1}

A 37-year-old female underwent GBP surgery for morbid obesity (height $175 \mathrm{~cm}$, weight $106 \mathrm{~kg}$, body mass index, BMI, $42 \mathrm{~kg} / \mathrm{m}^{2}$ ). A bilateral subcostal incision was used for this surgery. Seven years later, she presented for abdominoplasty and excess skin resection (weight loss $23 \mathrm{~kg}$, weight $83 \mathrm{~kg}$, BMI 34 $\mathrm{kg} / \mathrm{m}^{2}$ ) (Figure 2).

Perforator-sparing abdominoplasty was performed as described above with two major periumbilical perforators (latero-cephalad to the umbilicus) dissected, with tunneling through the rectus fascia and muscles and ligation of the cephalad branch of each perforator. The postoperative course was uneventful with good wound healing (Figure 3). Postoperative duplex imaging showed blood-flow in both dissected perforators (Figure 4).

\section{Case 2}

A 32-year-old female underwent GBP surgery for morbid obesity (height $160 \mathrm{~cm}$, weight $130 \mathrm{~kg}$, BMI $50.8 \mathrm{~kg} / \mathrm{m}^{2}$ ). A bilateral subcostal incision was used for this surgery. Two years later, she presented for abdominoplasty and excess skin resection (weight loss $58 \mathrm{~kg}$, weight $72 \mathrm{~kg}$, BMI $28.1 \mathrm{~kg} / \mathrm{m}^{2}$ ).

Perforator-sparing abdominoplasty was performed as described above with three major periumbilical perforators (two lateral to the umbilicus, one cranio-lateral to the umbilicus) dissected, with tunneling through the rectus fascia and muscles and ligation of the cephalad branch of each perforator (Figure 5). The postoperative course was uneventful with good wound healing. 

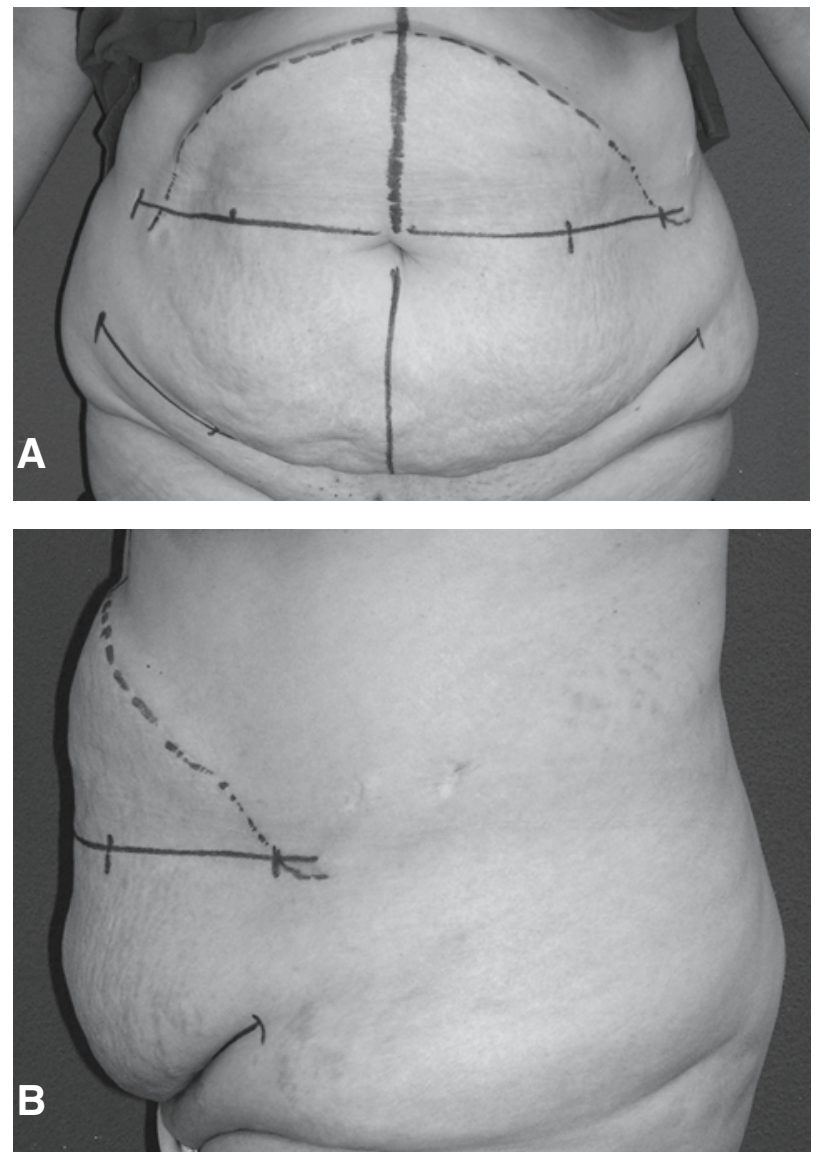

Figure 2. Preoperative views (the bilateral subcostal scar is indicated with a dotted line): A. frontal; B. lateral.

\section{Results}

Both cases had uneventful postoperative courses and were successful in terms of the aesthetic result. Blood supply through the dissected perforator vessels was proven by color-flow duplex imaging (blood-flow is indicated by red and yellow color).

\section{Discussion}

Extended flap undermining is the surgical standard in abdominoplasty. Nine out of ten plastic surgeons reported that they performed complete undermining up to the costal margin. ${ }^{10}$ Reports describing limited dissection of the abdominal flap in a triangular shape from the xiphoid to anterior superior iliac spine, ${ }^{11}$ with discontinuous undermining by dissect-
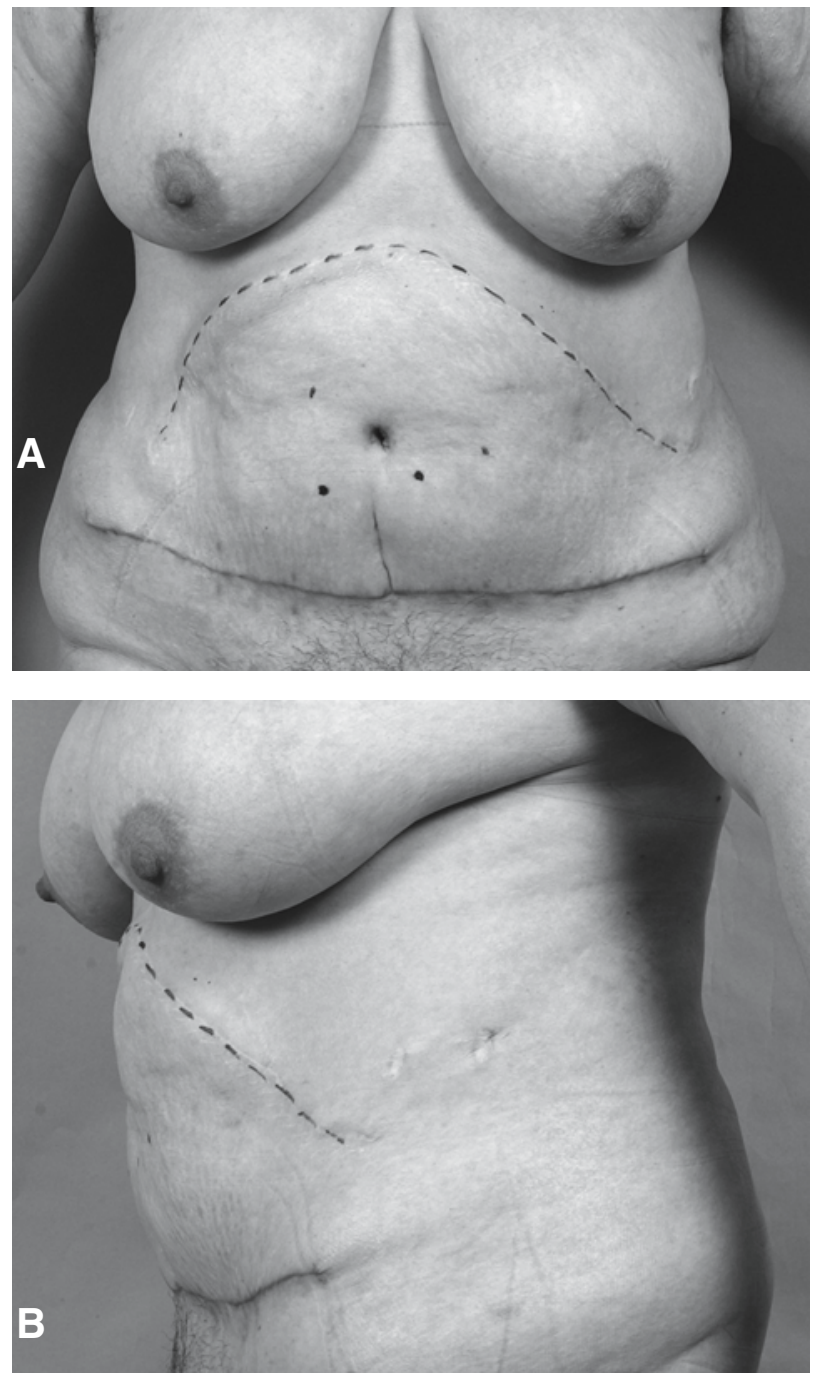

Figure 3. Postoperative views 6 weeks after abdominoplasty: A. front view: two major black dots indicate the two dissected perforator vessels that were detected by color duplex imaging; B. anterolateral view.

ing the supraumbilical flap by liposuction, ${ }^{12}$ have been described to improve flap perfusion. In these reports, adequate flap mobility was achieved with good flap perfusion by arterial perforators. ${ }^{12-14}$

However, in patients being referred for abdominoplasty after GBP, a long transverse supraumbilical or subcostal scar is occasionally encountere ${ }^{15}$ that compromises blood supply from the superior epigastric arteries. In a study by De Castro et $\mathrm{al}^{5}$ on full abdominoplasties on previously scarred abdomens, the authors claimed that the supraumbilical scar is a significant problem, and they considered it to be a considerable limitation for abdominoplasty due to a 


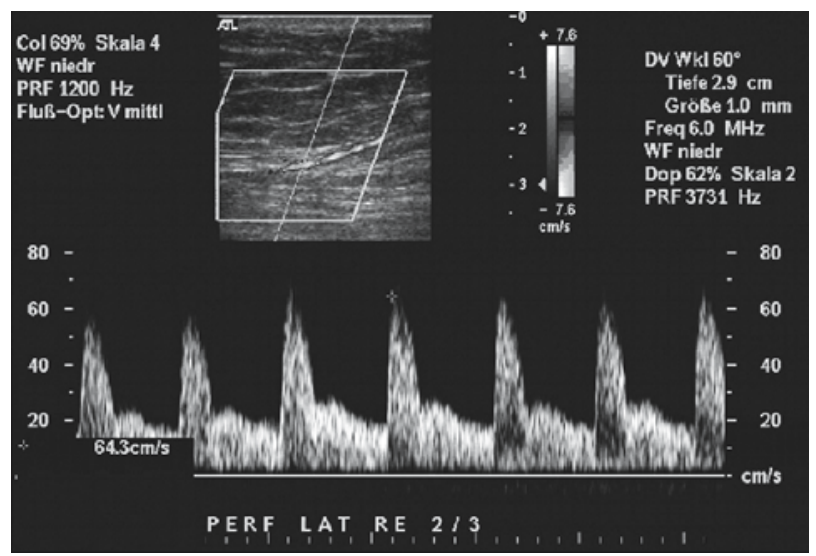

Figure 4. Blood-flow through dissected perforator vessel visualized by color-flow duplex imaging 10 weeks postoperatively.

higher rate of postoperative complications. One risk factor that is responsible for jeopardizing the blood supply of the abdominal flap is the existence of these previous scars and the subsequent subdermal fibrosis. Propositions have been made to limit the extent of mobilization of the abdominal flap to preserve the vascular zones. ${ }^{6}$ A fluorescence perfusography study from Germany on effects of abdominoplasty on abdominal wall perfusion showed significant impairment of vascular supply of the so-called zone 1 in all patients. ${ }^{16}$ Saulis et al ${ }^{17}$ have reported a significant reduction of postoperative wound complications in midline ventral hernia repairs by preservation of peri-umbilical rectus abdominis perforator vessels. Selective dissection and preservation of one perforator vessel from the inferior epigastric artery has been described in a patient with no risk factors undergoing aesthetic abdominoplasty. The effect was visualized by indocyanine green perfusography. ${ }^{16}$ Through this technique the blood supply of the abdominal flap may be changed from a random pattern into an axial pattern blood supply.

This assumption gains significant importance when the random pattern blood supply is compromised by oblique subcostal incisions. Oscar et al ${ }^{18}$ have described a rat model that showed that most of the abdominal rat skin could survive through the supply of a single musculo-cutaneous perforator vessel. This is consistent with the clinical experience that we have had with the deep inferior epigastric perforator flap (DIEP). Schoeller et al ${ }^{19}$ have reported a case of successful raising of a DIEP flap for breast reconstruction in a patient with subcostal
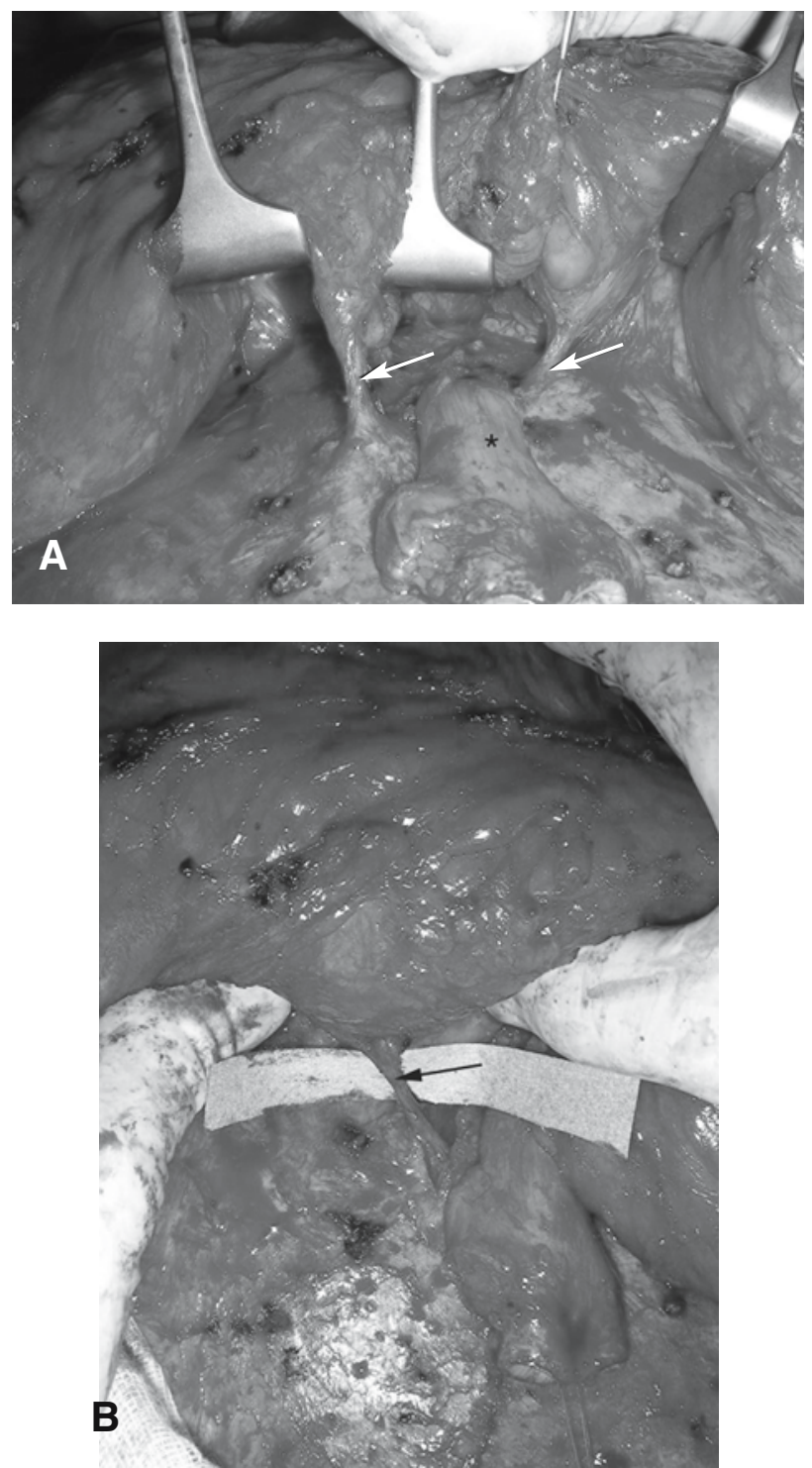

Figure 5. Intraoperative Views: A. Two dissected paraumbilical perforator vessels (arrows) and umbilicus (marked *); B. Perforator (arrow) cranio-lateral to umbilicus.

scars and successful wound closure by dissecting one single perforator to provide perfusion for the distal part of the cranial abdominal flap below the scar for wound closure. This finding of safe abdominal flap preparation is consistent with our experience with the two described cases of perforatorsparing abdominoplasty in patients with bilateral subcostal scars after open GBP.

As previously described, ${ }^{20}$ patients requiring surgical skin excision after massive weight loss for functional and/ or aesthetic reasons are challenging, and require individualized approaches. We believe 
that preoperative marking of perforators in the proximity of the umbilicus by color duplex imaging can help find the necessary perforator vessels, ${ }^{7}$ which may be of great use to a microsurgically less-experienced surgeon. Our approach shows that the distinct use of sonographic equipment enhances not only microsurgical flap surgery, but also may be of great use in abdominoplasty. We recommend a customized approach using duplex imaging for any "non-standard" abdominoplasty to enhance safety.

Although massive weight loss improves health status in general, the formerly obese patients still often carry significant residual co-morbidities, such as hypertension, diabetes or hypercholesterolemia. ${ }^{19}$ Through an adequate surgical technique, excellent results can be achieved even in the presence of these co-morbidities using the described perforator-sparing technique. In none of our cases was flap survival or wound healing a problem.

In conclusion, our concept of improving blood supply to the abdominal flap by selective dissection of perforator vessels in patients with bilateral subcostal scars, which enables us to perform a full abominoplasty with complete flap undermining, has not been described before. By color-flow duplex imaging, we show that a major blood supply comes from the dissected perforators.

We suggest that our perforator-sparing abdominoplasty technique should be considered as a treatment option in patients after open GBP with oblique subcostal incisions. Furthermore, we recommend preoperative color flow duplex mapping of the abdominal wall for microsurgically less-experienced surgeons, for easier detection of perforator vessels for "non-standard" abdominoplasties.

We thank Stefan De Maddalena for excellent photo documentation.

\section{References}

1. Savage RC. Abdominoplasty following gastrointestinal bypass surgery. Plast Reconstr Surg 1983; 71: 500-9.

2. Alvarez-Cordero R, Aragon-Viruette E. Incisions for obesity surgery: a brief report. Obes Surg 1991; 1: 40911.

3. Jones KBJ. The superiority of the left subcostal incision compared to mid-line incisions in surgery for morbid obesity. Obes Surg 1993; 3: 201-5.
4. Jones KBJ. The left subcostal incision revisited. Obes Surg 1998; 8: 225-8.

5. de Castro CC, Aboudib JJ, Salema R et al. How to deal with abdominoplasty in an abdomen with a scar. Aesthetic Plast Surg 1993; 17: 67-71.

6. Huger WEJ. The anatomic rationale for abdominal lipectomy. Am Surg 1979; 45: 612-7.

7. Pitanguy I, Mayer B, Labrakis G. [Abdominoplasty personal surgical guidelines] Zentralbl Chir 1988; 113: 765-71. German.

8. Chang BW, Luethke R, Berg WA et al. Two-dimensional color Doppler imaging for precision preoperative mapping and size determination of TRAM flap perforators. Plast Reconstr Surg 1994; 93: 197-200.

9. Rand RP, Cramer MM, Strandness DEJ. Color-flow duplex scanning in the preoperative assessment of TRAM flap perforators: a report of 32 consecutive patients. Plast Reconstr Surg 1994; 93: 453-9.

10. Grazer FM, Goldwyn RM. Abdominoplasty assessed by survey, with emphasis on complications. Plast Reconstr Surg 1977; 59: 513-7.

11. Baroudi R, Keppke EM, Netto FT. Abdominoplasty. Plast Reconstr Surg 1974; 54: 161-8.

12. Illouz YG. A new safe and aesthetic approach to suction abdominoplasty. Aesthetic Plast Surg 1992; 16: 237-45.

13. Matarasso A. Liposuction as an adjunct to a full abdominoplasty. Plast Reconstr Surg 1995; 95: 829-36.

14. Matarasso A. Liposuction as an adjunct to a full abdominoplasty revisited. Plast Reconstr Surg 2000; 106: 1197-202; discussion 1203-5.

15. Jones KB, Afram JD, Benotti PN et al. Open versus laparoscopic Roux-en-Y gastric bypass: a comparative study of over 25,000 open cases and the major laparoscopic bariatric reported series. Obes Surg 2006; 16: 721-7.

16. Mayr M, Holm C, Hofter E et al. Effects of aesthetic abdominoplasty on abdominal wall perfusion: a quantitative evaluation. Plast Reconstr Surg 2004; 114: 1586-94.

17. Saulis AS, Dumanian GA. Periumbilical rectus abdominis perforator preservation significantly reduces superficial wound complications in "separation of parts" hernia repairs. Plast Reconstr Surg 2002; 109: 2275-80 ; discussion 2281-2.

18. Oksar HS, Coskunfirat OK, Ozgentas HE. Perforatorbased flap in rats: a new experimental model. Plast Reconstr Surg 2001; 108: 125-31.

19. Schoeller T, Huemer GM, Kolehmainen M et al. Management of subcostal scars during DIEP-flap raising. Br J Plast Surg 2004; 57: 511-4.

20. Taylor J, Shermak M. Body contouring following massive weight loss. Obes Surg 2004; 14: 1080-5.

(Received July 10, 2006; accepted September 2, 2006) 